\title{
PRICES OF ACCOMMODATION RENTAL AS FUNCTIONING ON THE BASIS OF A SHARING ECONOMY IN THE CAPITALS OF CEE STATES
}

\begin{abstract}
Housing rental from private resources, thanks to the growing popularity of a sharing economy, is becoming more and more common. The principles of market activities compliant with the assumptions of a sharing economy create new frameworks in the science of economics, simultaneously subjecting classical methods and tools of management to verification. Making use of new information technologies and peer-to-peer technology, which as part of the former, has facilitated using a sharing economy in the hotel industry, creating a new community in the rental of housing market - people providing services of short-term renting of private accommodation facilities. The conducted research presents one-day rental (of the Bed \& Breakfast type) functioning in compliance with the principles of a sharing economy. Its parametrization was carried out in the area of the formation of prices and their distribution. The resources of $\mathrm{B} \& \mathrm{~B}$ rental were examined in the capital cities of Central and Eastern Europe. For each city the average prices of rental were determined, as were the average prices of extra services provided within the business activity (i.e. mean service charges and mean charges for cleaning). Additionally, a comparative analysis was carried out regarding the pricing of average rental costs with a simultaneous study of the significance of the differences observed in them. The conducted research allowed defining the structure of the total price of rental, which is composed of the price of the rental displayed on the webpage including offers of $\mathrm{B} \& \mathrm{~B}$ rental and additional charges, i.e. the service and the cleaning fees. It follows from the conducted research, among others, that about one-third of the offered housing rental resources did not charge fees for cleaning and that the mean total price of housing rental for all the capitals of European the post-communist states ranged between 50 and 60 euros per night. From the point of view of the mean total rental price, the most expensive cities are Tallinn and Bratislava, whereas the cheapest countries are Bulgaria and Romania. The mean total rental prices for the capitals of Bulgaria and Romania are considerably lower than in the other capital cities of European post-communist states.
\end{abstract}

Keywords: sharing economy, real estate, accommodation rental, peer-economy, price level, Central and Eastern Europe

JEL Classifications: R10, R31, Z32

DOI: 10.15611/aoe.2020.2.06

\footnotetext{
* Faculty of Economics and Management, Opole University of Technology.
} 


\section{INTRODUCTION}

Thanks to the application of information technologies, booking short-term accommodation has become a very easy procedure nowadays: it suffices to enter the relevant website, browse and select one of the thousands of available offers, contact the owner of the chosen estate and settle conditions of rental in detail. Using the peer-to-peer technology, the above-described series of actions are not limited by geolocation aspects, exchange rates or language barriers (in view of the fact that the offers of accommodation are presented in many languages). Consequently, new technologies and new business ideas have contributed to the appearance of a new community in the market of rented accommodation resources. The largest community of this type includes 200 million visitors and comprises offers of rental from over 65 thousand cities in 191 states $^{1}$. This community, availing itself of the principles of sharing economy, has become a serious competition which challenges the hotel business today as well as the theories and models used in it. The new rental service, referred to as one-day renting or Bed \& Breakfast (B\&B) rental in this article, is a dynamically growing market which is in line with the principles of sharing economy. This trend has introduced changes (and will continue to do so) into the classical models of business activity.

This study undertakes to parameterize the private one-day rental market in the scope of pricing the accommodation facilities on offer. The range of the analyses includes the capitals of EU countries in Central and Eastern Europe (CEE), namely Bratislava, Bucharest, Budapest, Prague, Riga, Sofia, Tallinn, Vilnius and Warsaw. More precisely, the study deals with rentals, service charges and extra fees (e.g. cleaning and maintenance of flats). Additionally, the distribution of the prices was examined and analysed. The analysis of distributions allowed for examining the structure of prices of the facilities on offer. It needs noting that in the process of examining the prices, the statistical significance of the differences calculated for the offered rental between individual capitals, was assessed as well. The conducted research allowed to answering the following question: are there, in the capital cities of postcommunist countries which have been functioning within a market economy and the EU structures for a relatively short time, any similar or significant differences in the prices of private one-day accommodation rental on offer? The type of rental is that registered based on a sharing economy. This allowed for presenting the distribution of pricing, which - in turn - makes it possible

\footnotetext{
${ }^{1} \mathrm{https}: / /$ www.airbnb.com/about/about-us.
} 
to define the price structure of the resources. Consequently, knowing the structure will facilitate analysing the preferences of people renting the accommodation from the point of view of the charges they pay.

\section{THEORETICAL BACKGROUND}

An analysis of the literature of the subject was carried out, concentrating on the thematic range of the conducted study, that is the latest research in the sphere of a sharing economy. The problem of one-day accommodation rental, which is directly connected with the former, was examined accordingly. The analysis of the literature focused on aspects concerning the impact of a sharing economy on the economic system and on creating business models which are relevant to it. Research was presented in the form of guidebooks or recommendations in the sphere of a sharing economy, showing the lines of its development , and the possibility of applying a sharing economy in the socioeconomic, legal and sociological dimensions was also indicated. Additionally, the analysis of the literature focused on the dilemmas of measuring the level of trust and reputation existing on the B\&B rental market. Studies which determine price-setting factors as well as price convergence in selected localities were also presented. In his research, Martin (2016) stresses that peer-to-peer technology makes it possible to provide services based on the assumptions of a sharing economy, at the same time pointing to possible directions of the development of economic reality that take into account the principles of a sharing economy, therefore changes in economic models from sustainable development through an economy based on the principles of neoliberalism. The described studies shed light on the possibility of the threat posed to contemporary economic systems, which consists in the decreasing role of the state as the regulator of the economy. Dyal-Chand (2015) defines the philosophy of a sharing economy as an alternative to capitalism. In another study, Daunorienė et al. (2015) make an attempt at elaborating on a business model which goes in line with the principles of the working of a sharing economy, while indicating the durability of this model and its impact on sustainable development. Another work dealing with sharing economy by Guttentag, Smith (2017),points to a real threat to the traditional business model, since in the hotel industry it is not adjusted to the philosophy of working that is based on a sharing economy. There are also publications which are a particular type of guidebooks or which offer recommendations to managers advising on how to apply a sharing economy in business (cf. Habibi et al. 2017) and show possible lines for the development of future research in the sphere of an economy of this type (Cheng 2016). Lastly, in recent years 
a sharing economy has been widely described in the literature with reference to socioeconomic (cf. Wu, Zhi 2016; Kung, Zhong 2017; Frenken, Schor 2017), legal (cf. Frenken, Schor 2017; Koopman et al. 2015; Ranchordas 2014) and sociological dimensions (cf. Gregory, Halff 2017; Böcker, Meelen 2016).

In considering a sharing economy in the framework of the Airbnb platform, one can indicate studies which describe and measure the level of reputation and trust in services of the peer-to-peer type as regards the aspect of the renting which is taking place (Ert et al. 2016). Other research also provides an answer to the question of the impact of a sharing economy on the employment market particularly in the tourist industry (Fang et al. 2016). The studies by Wang and Nicolau (2017) attempt to determine the factors which influence the level of prices of one-day accommodation facilities. On the other hand, in their work, Liang et al. (2017) investigate the validity of the rating system by clients who take advantage of the rental and their influence on the functioning of the oneday rental market. An analysis of the convergence of ratings for three localities was executed, which consisted in analysing offers on the Airbnb service (cf. Brochado et al. 2017). In other studies which are noteworthy, Varma et al. (2016) discussed the question of whether the use of a sharing economy via

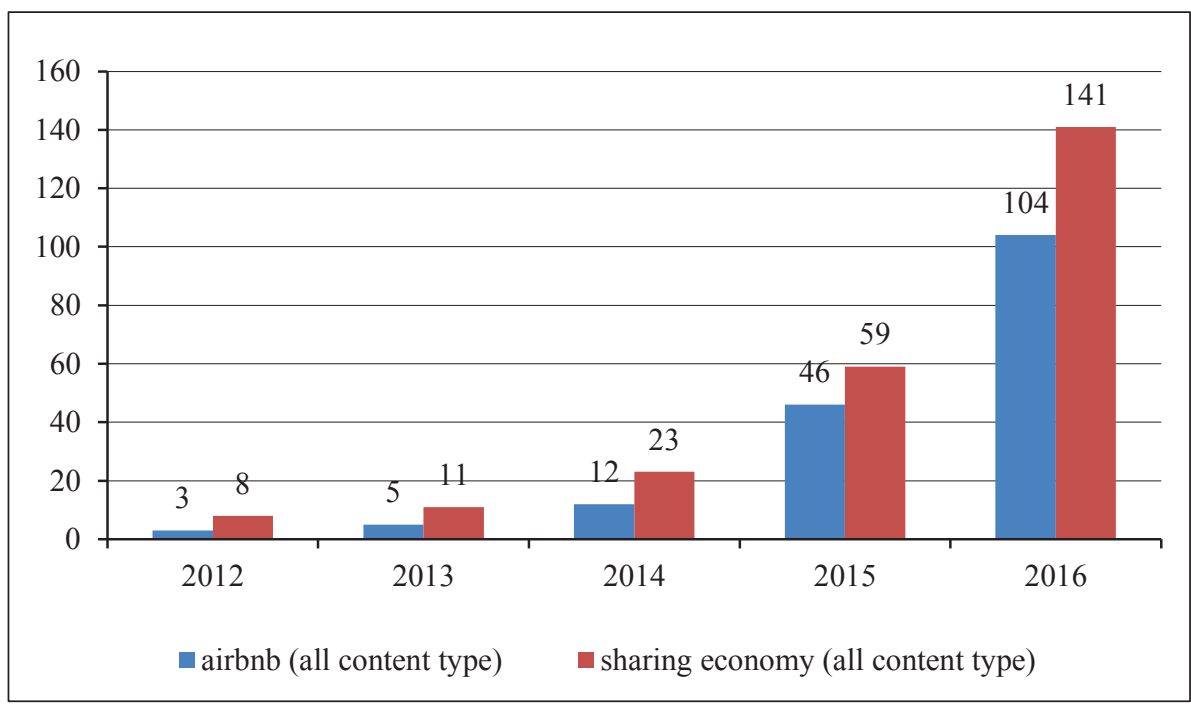

Fig. 1. The number of scientific publications dealing with a sharing economy and describing rental of accommodation via Airbnb

Source: own study based on sciencedirect.com. 
Airbnb is a new wave of innovativeness or only a temporary fad. It also needs noting that - as in the case of every object of economic analysis - there appears criticism of the functioning of economic systems based on the principles of the working of a sharing economy (cf. Cockayne 2016; Kathan et al. 2016).

In the final part presenting the analysis of the literature of the subject, Figure 1 shows the number of scientific publications dealing with a sharing economy and describing the rental of accommodation via Airbnb. The data presented in the chart confirm the fact that there is a growing interest in the phenomenon of a sharing economy as well as in renting accommodation with the use of Airbnb. In this part of the analysis, it is necessary to underline the need for conducting further studies into the sphere in question, particularly placing them within the area of CEE. Looking at the number of articles on the sciencedirect.com platform which deal with any subject relating to CEE countries, in 2016 there were 13 of them, none of which explored the area of studies on the B\&B rental type. The above-mentioned fact confirms the necessity or even indispensability of realizing the research described in this article.

\section{RESEARCH ASSUMPTIONS AND METHODOLOGY}

The studies dealing with assessment of prices of renting private accommodation resources in the capitals of nine CEE states were carried out at three stages. The first (described in Section 3) presents the initial statistical analysis conducted for the whole studied sample taking into account relevant data from all the examined capital cities. The research at the first stage focused in particular on analysing the average rental prices, including the distribution of prices of renting a place, the service surcharge paid to the Internet service and the extra fee for cleaning. The next stage (see Section 4), presents a more detailed analysis which consists in examining the distribution of the total costs of rental for each capital city. The analysis of prices distribution allowed to present the price structure of the rented resources, which points to which places are most frequently rented (cheap, medium-priced or those more expensive). Then, at the third stage (cf. Section 5), the mean prices of accommodation rental are compared for the examined capital cities, simultaneously checking the significance of the differences existing in them.

It should be mentioned that the price analysis was carried out on the assumption that the accommodation was rented for two adults booking ii for the last weekend of March 2017. Despite the fact that the examined accommodation was to cover the whole weekend, to illustrate the presentation better and make it more readable, the prices of renting were re-calculated for 
one night. The prices are given in euros. The offers of rental were obtained from the Internet service Airbnb.com, from which the parameters of 450 housing rental offers were analysed (50 offers of rental for each of the nine examined cities).

As regards the methodology of the applied research methods, it needs explaining that in stages 1 and 2, the values of the mean prices, standard deviation, the minimum and maximum values, quadrant measurement of location in the form of the lower and upper quartiles, and the median, were calculated for the needs of the analysis. Additionally, the 95\%-wide range of trust was calculated for the value of the mean price and, accordingly, bar charts as well as box plots were created (with the aim to present the distribution of prices). The presented basic measures of descriptive statistics were calculated in compliance with the commonly binding rules of calculations. The detailed principles behind the calculations can be found in Freedman et al. (1980) and Aczel (1989). At the third research stage, in order to check the significance of the differences in the calculated means, the analysis of variance (ANOVA) was used. The ANOVA-based calculations were carried out in compliance with the formal guidelines found in the study by Aczel (1989). Making the calculations more precise with the use of analysis of variance, it must be remembered that this is a statistical method which serves to compare the mean in several populations. It was applied to test the significance of the differences in the mean prices of the offers as calculated for the nine examined capitals of the post-communist countries. For the needs of this study, a system of hypotheses was constructed. They are described using Equation 1.

$$
\begin{gathered}
H_{0}: \mu_{1}=\mu_{2}=\mu_{3}=\mu_{4}=\mu_{5}=\mu_{6}=\mu_{7}=\mu_{8}=\mu_{9} \\
H_{1}: \text { not all } \mu_{i}(i=1, \ldots, 9) \text { areequal }
\end{gathered}
$$

The object of the study is $r=9$ of the populations (the capital cities) with the total number in the sample amounting to $n=450$ observations calculated from Equation 2.

$$
n=n_{1}+n_{2}+n_{3}+n_{4}+n_{5}+n_{6}+n_{7}+n_{8}+n_{9}
$$

It was assumed in the analysis that the samples of the population were taken independently of one another and also that in each of the examined populations the distribution is regular, with the same variance and that the mean values can, but do not have to be equal. The test applied in the conducted analysis, assuming that the zero hypothesis is true, had distribution $F$ with $(r-1)(n-r)$ degrees of freedom, where $r$-number of examined capital cities, $n$ - number of all observations (see Equation 3). 


$$
F_{(r-1, n-r)}=\frac{M S T R}{M S E}
$$

In order to find the mean square deviations resulting from the treatments and from the errors, the authors divide the relevant sums of quarters by the numbers of the degrees of freedom related to them. The averages which were the results of these operations were called the mean square treatment result (MSTR) and the mean square error (MSE), which were calculated according to Equations 4 and 5.

$$
\begin{aligned}
M S T R & =\frac{S S T R}{r-1} \\
M S E & =\frac{S S E}{n-r}
\end{aligned}
$$

Equations 6 and 7 should be used in further calculations.

$$
\begin{aligned}
& S S E=\sum_{i=1}^{r} \sum_{j=1}^{n_{i}}\left(x_{i j}-\bar{x}_{i}\right)^{2} \\
& S S T R=\sum_{i=1}^{r} n_{i}\left(\bar{x}_{i}-\overline{\bar{x}}\right)^{2}
\end{aligned}
$$

where: $x_{i j}$ - the particular data point in position $j$ within the sample from population $i, \bar{x}_{i}-$ mean of population $i, n_{i}$ - number of observations in sample $I$, where $i=1 . .9, \overline{\bar{x}}$ - grand mean, $r$-number of populations.

\section{INITIAL STATISTICAL DESCRIPTIVE ANALYSIS - CENTRAL AND EASTERN EUROPE}

Executing the statistical analysis of the rental price (the price not including the additional service charge or that for cleaning) for all the capitals of the CEE states, one can notice that the mean price of the offer amounts to EUR 20.14 per facility per day. The minimum price recorded for the examined resources per day was EUR 4.55, while the maximum amounted to EUR 48.32. It should also be mentioned that in the case of $25 \%$ of the accommodation resources, the offered price was lower than EUR 14.43, and another 25\% charged more than EUR 25.26. Carrying out the analysis of the distribution of the prices charged, one can notice that the price distribution is of a rightskewed character. The largest number of transactions can be noted within the price range EUR 10-15 and EUR 15-20 (Szapiro-Wilk; $p<=0.00001$ ). It needs 
remembering, however, that in order to calculate the total price charged for the rented accommodation (the final price to pay) it is necessary to add the socallesd service charge (cf. Figure3) and the fee charged for cleaning(cf. Figure4) to the price of rental per night (as presented in Figure2).

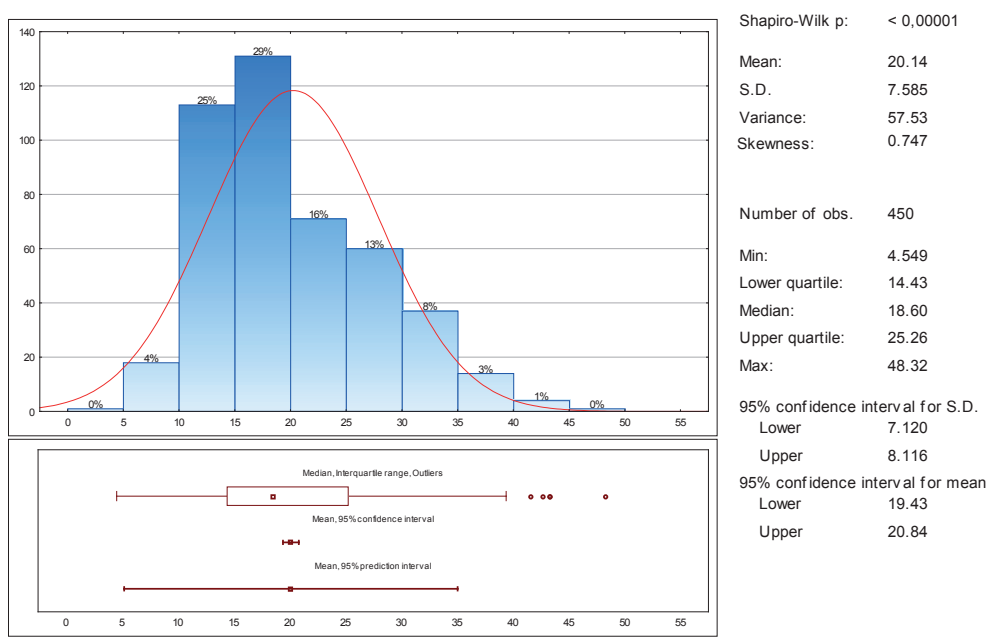

Fig. 2. Initial statistical analysis - price per night/day - Central and Eastern Europe Source: own study based on calculations in Dell ${ }^{\mathrm{TM}}$ Statistica $^{\mathrm{TM}}$.
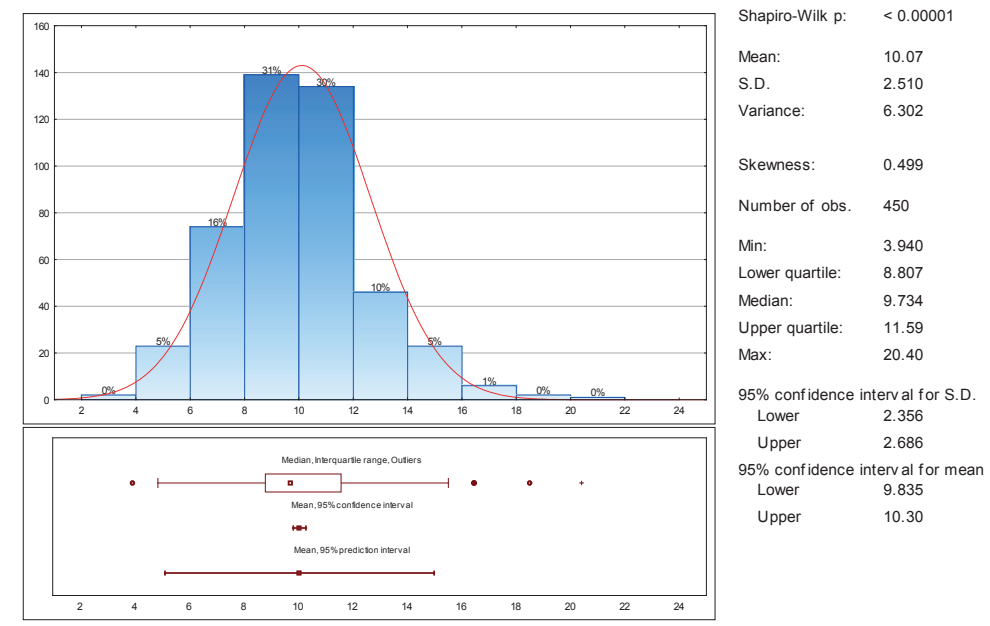

Fig. 3. Initial statistical analysis - price per additional service - Central and Eastern Europe Source: own study based on calculations in Dell ${ }^{\mathrm{TM}}$ Statistica ${ }^{\mathrm{TM}}$. 
Analysing the extra charges, it is possible to notice that on the average it is necessary to pay EUR 10.07 for the additional service (cf. Figure3) and EUR 8.87 for cleaning (cf. Figure4) to the offered price of rental. It must be

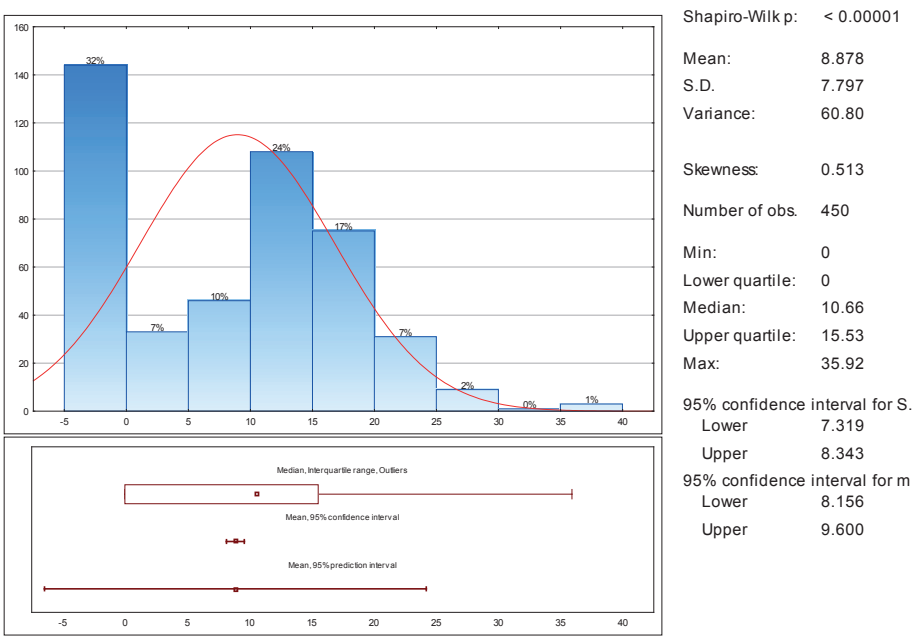

Fig. 4. Initial statistical analysis - price per cleaning - Central and Eastern Europe Source: own study based on calculations in Dell ${ }^{\mathrm{TM}}$ Statistica $^{\mathrm{TM}}$.

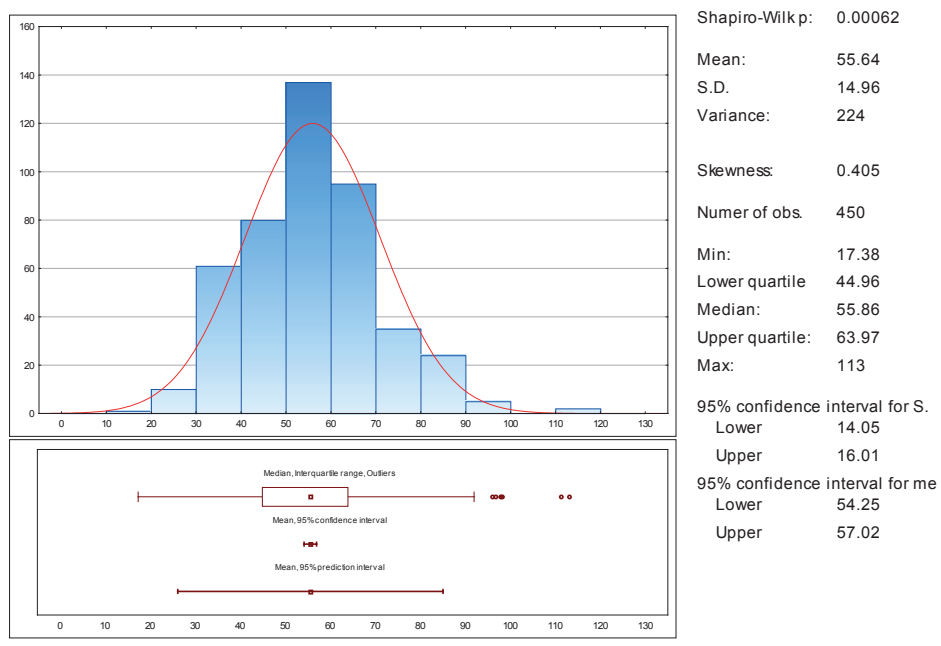

Fig. 5. Initial statistical analysis - total price per night/day - Central and Eastern Europe Source: own study based on calculations in Dell ${ }^{\mathrm{TM}}$ Statistica $^{\mathrm{TM}}$. 
noted that the latter charge did not feature in as many as $32 \%$ of the offers appearing in the AirBnB service. This fact implies that the lower quartile value for this component amounts to zero. Summing up, the above-presented analysis of rental prices and additional services, i.e. service charge and fee for cleaning in Figure 5 shows the total, i.e. ultimate price for rental of B\&B accommodation.

It shows the average total price of rental within the $\mathrm{B} \& \mathrm{~B}$ resources, in which the mean rental price amounted to EUR 55.64 per one night at the minimum price of EUR 17.38 and the maximum one of EUR 113.

\section{ANALYSIS OF DISTRIBUTION OF TOTAL PRICES OF RENTAL}

In this section the distribution of total prices of the rented facilities found in the nine capitals of CEE states is presented (i.e. the process including a charge for rental, service fee and - possibly the fee charged for cleaning. Sofia was analysed first. The mean total price of a short-term rental of B\&B type in the capital of Bulgaria was EUR 49.38, the minimum price being EUR 17.38 and the maximum one - EUR 65.13. It needs noting that $25 \%$ of the offers were lower than EUR 40.56, whereas 25\% were higher than EUR 57.94. The distribution of the examined feature displays the character of a left-skewed one. This implies the fact that the majority of accommodation facilities on offer are characterized by a high price: $32 \%$ remain within the range of EUR 55-60, while $56 \%$ of the resources on offer are within the range of EUR 50-65. In Sofia, there also appeared offers of rental at a very low price; $2 \%$ of the resources remained in the price range between 15 and 20 euros. Detailed calculations are presented in Figure 6 including the basic descriptive statistics relevant for the distribution of total rental prices for the capital of Bulgaria.

The next examined city was Budapest (the capital of Hungary), where the average short-term rental price amounts to EUR 56.37, at the minimum total price - EUR 42.88 and the maximum one - EUR 68.60. It must be added that $25 \%$ of the offered accommodation was cheaper than EUR 50.99. In the case of Budapest, the distribution of the presented total prices is symmetric. The largest number of offers is for rented accommodation at the total price EUR 5055 and EUR $65-70$, i.e. $24 \%$ and $20 \%$, respectively. In Budapest, making a graphic assessment of the obtained distribution of prices, one can notice that a relatively even distribution of the amount of rented accommodation was seen within the price range between 45 and 70 euros. A detailed analysis of the data within the range of descriptive statistics concerning the total rental prices for the city of Budapest is presented in Figure 7. 


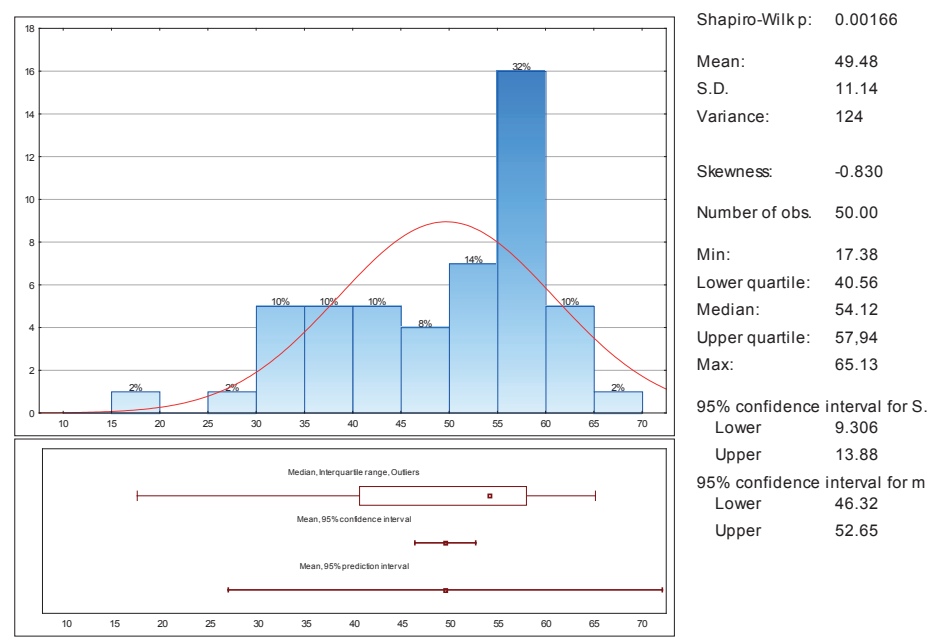

Fig. 6. Analysis of the total price distribution for the city of Sofia

Source: own study based on calculations in Dell ${ }^{\mathrm{TM}}$ Statistica $^{\mathrm{TM}}$.

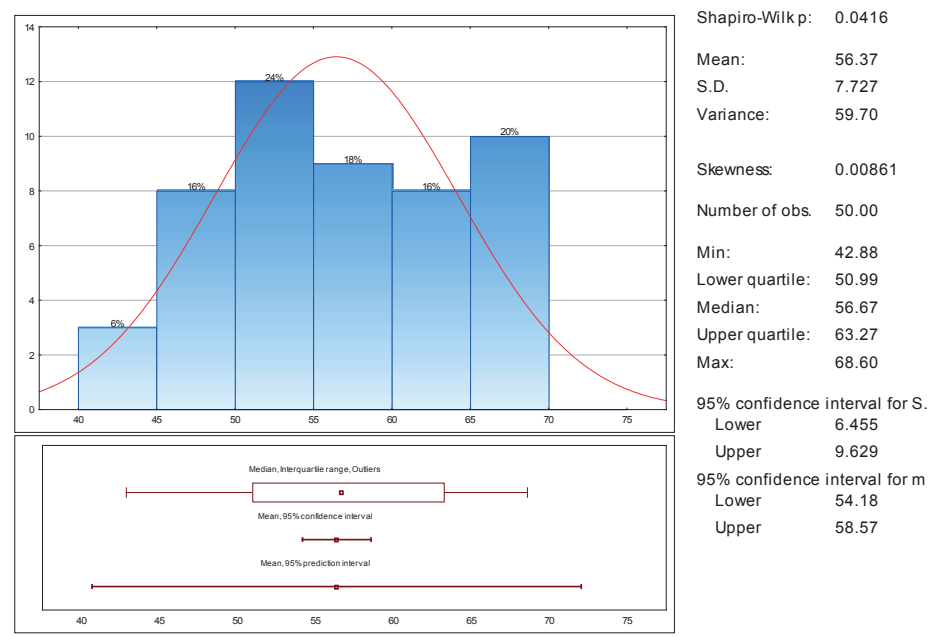

Fig. 7. Analysis of the total price distribution for the city of Budapest

Source: own study based on calculations in Dell ${ }^{\mathrm{TM}}$ Statistica $^{\mathrm{TM}}$.

Bucharest (the capital of Romania) was the next capital analysed. The mean total short-term rental price amounts here to EUR 43.04, at the minimum total price - EUR 20.63 and the maximum one - EUR 70.69. In this city, 25\% 
of the prices are below EUR 36.62 and 25\% - above EUR 50.29, and the distribution is symmetric, while the highest number of offered rentals remains within the range of EUR 35-40, EUR 40-45 and EUR 50-55, which yields $22 \%, 18 \%$ and $18 \%$, respectively. In Bucharest, it should be mentioned, $4 \%$ of the resources are characterized by relatively high prices (the price ranged from 65 to 70 euros) - see Figure 8.

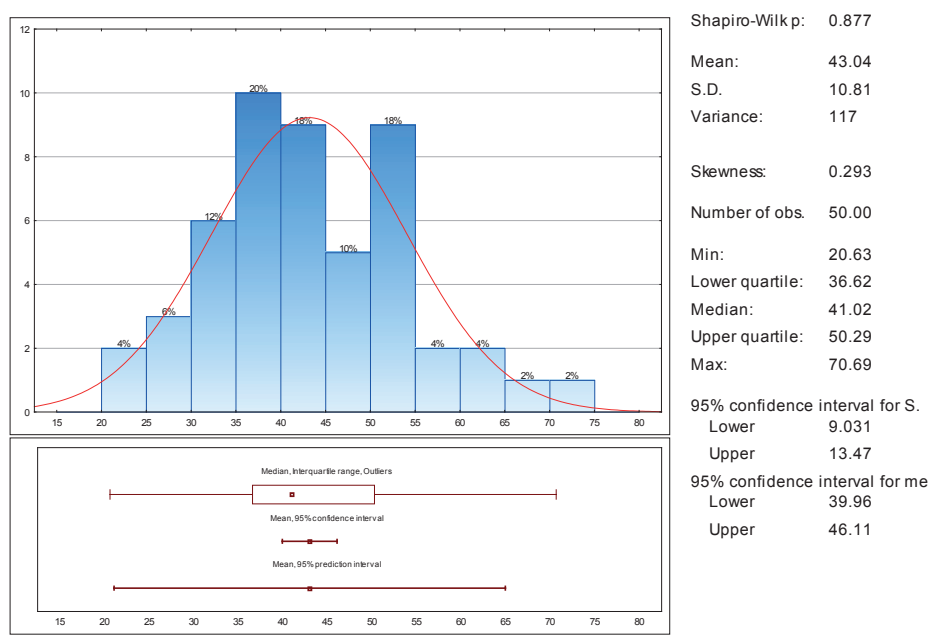

Fig. 8. Analysis of the total price distribution for the city of Bucharest

Source: own study based on calculations in Dell ${ }^{\mathrm{TM}}$ Statistica $^{\mathrm{TM}}$.

The capital of Slovakia, Bratislava, was the next of the cities for which an analysis of total prices of rental of private housing resources was carried out. The distribution of the total prices for this city is normal (Shapiro-Wilk test, $p=0.13$ ), and this regularity causes the largest number of the recently offered prices in the market to be close to the mean. The mean total price for Bratislava amounts to EUR 60.09, at the observed total minimum and maximum prices being EUR 30.59 and EUR 87.61, respectively. The largest number of total rental prices were offered within the range of EUR 60-65 (24\%). The basic descriptive statistics and characteristics of plot-box graphs are presented in Figure 9.

The next city examined, located close to Bratislava, is Prague - the capital of the Czech Republic. The mean total rental price here is slightly lower than that for Bratislava and amounts to EUR 56.89. The value of the median amounts to EUR 58.29, which implies the fact that $50 \%$ of the offers are over/ below this value. Those intending to rent short-term accommodation in that 

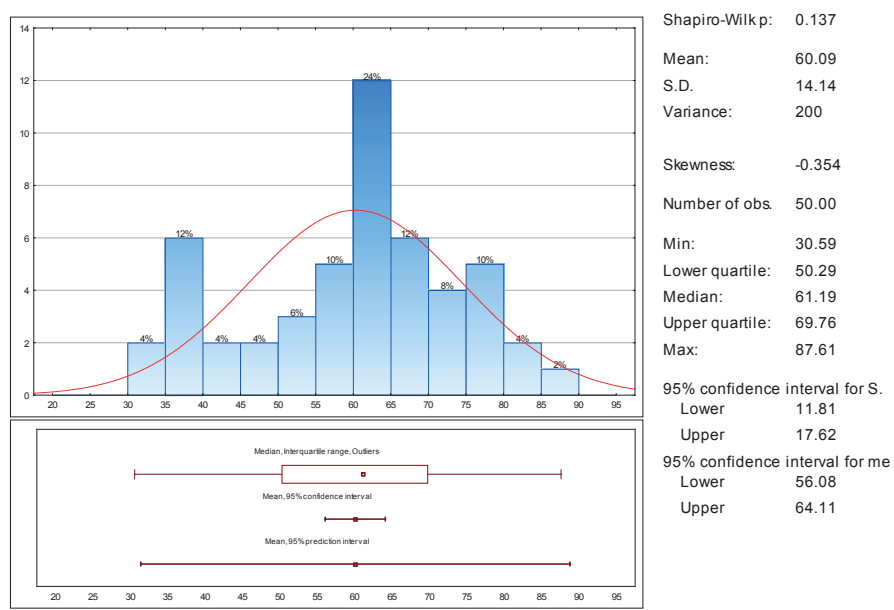

Fig. 9. Analysis of the total price distribution for the city of Bratislava

Source: own study based on calculations in Dell ${ }^{\mathrm{TM}}$ Statistica ${ }^{\mathrm{TM}}$.

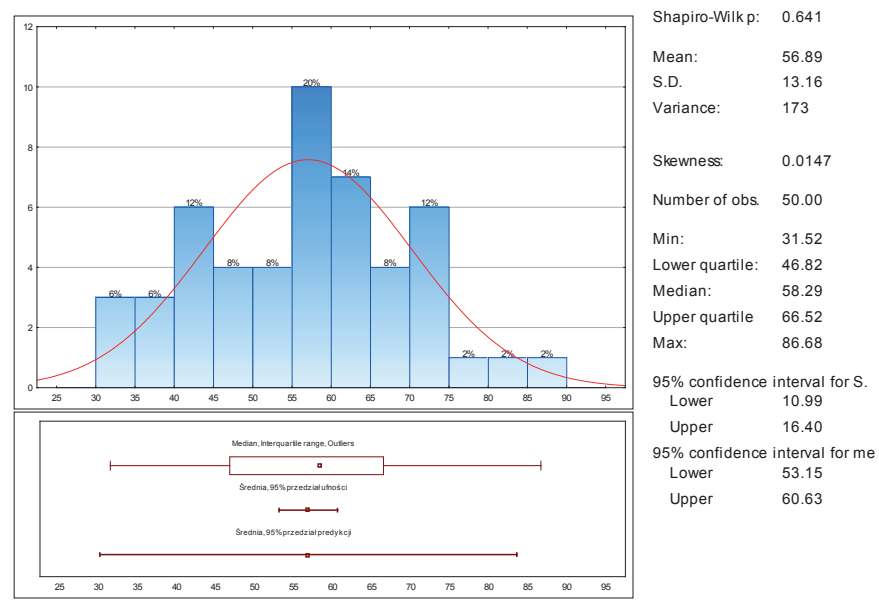

Fig. 10. Analysis of the total price distribution for the city of Prague

Source: own study based on calculations in Dell ${ }^{\mathrm{TM}}$ Statistica $^{\mathrm{TM}}$.

market are able to find offers, $25 \%$ of which will be priced lower than or equal to EUR 46.82, while another 25\% - higher than EUR 66.52. In Prague, it needs stating, the offers of rental included $6 \%$ of the housing resources of relatively high prices (ranging from 75 to 90 euros) - see Figure 10. 
Figure 11 presents descriptive statistics, a histogram and plot-box diagrams calculated for the total rental price of housing resources of B\&B type for Tallinn - the capital of Estonia. According to Shapiro-Wilk, describing the agreement of rental prices distribution with the normal distribution, it should be acknowledged that they correspond with each other. This fact justifies putting forward the thesis that the biggest number of total rental prices come close to the mean value. The mean total price of the offers for Tallinn amounts to EUR 63.83, with the gap reaching EUR 66.06. The most expensive price was EUR 96.65, whereas the cheapest one - EUR 30.59. In Tallinn, 2\% of the resources which appeared in the rental offers were in the price range of EUR 90-100 which allows for making the premise that they are the highest. In constructing the graphic interpretation of the plot-box graphs, it should be stressed that regarding the examined city there were no rental offers acknowledged to be outliers or suspected of being so.

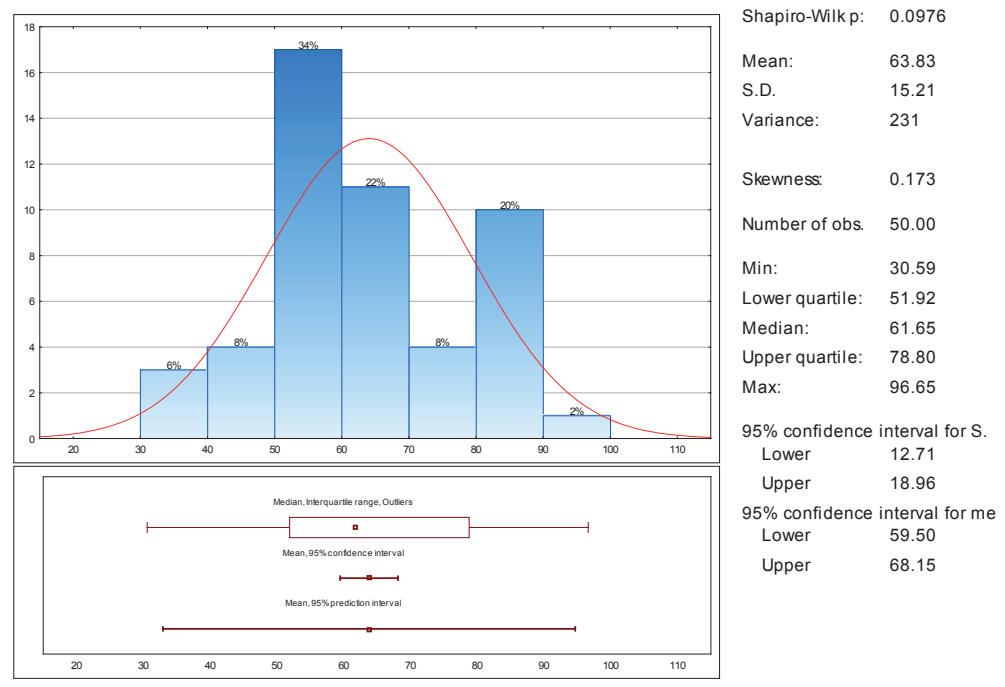

Fig. 11. Analysis of the total price distribution for the city of Tallinn

Source: own study based on calculations in Dell ${ }^{\mathrm{TM}}$ Statistica $^{\mathrm{TM}}$.

The next city under examination was Vilnius, the capital of Lithuania - a former republic of the Soviet Union. The mean total rental price here is on the level of EUR 55.81 (cf. Figure 12). The values of the lower and the upper quartiles amount to EUR 44.73 and EUR 64.43, respectively. Analysing the plot-box diagrams, it can be noted that in the rental market of Vilnius, there appear outliers ( 2 observations in 50 , which makes $4 \%$ of the offers), instances 
of a considerably higher total offered price than those appearing in the market. The total price distribution is a right-skewed one, the largest number being in the price range of EUR 40-50 (28\%) and EUR 50-60 (24\%).

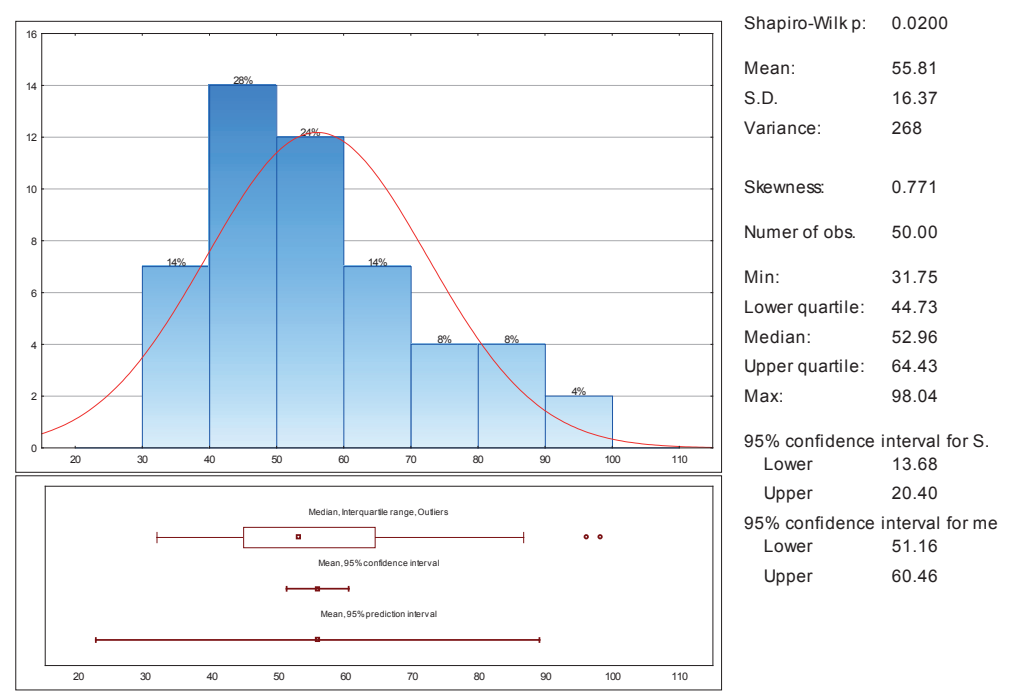

Fig. 12. Analysis of the total price distribution for the city of Vilnius

Source: own study based on calculations in Dell ${ }^{\mathrm{TM}}$ Statistica ${ }^{\mathrm{TM}}$.

The third examined capital city of a former Soviet republic - Latvia - was Riga (cf. Figure 13). The mean total price for this city remains on the level of EUR 57.21, at the minimum and the maximum total prices amounting to EUR 21.55 and EUR 113, respectively; 25\% are lower than EUR 39.17 and $25 \%$ of them - higher than EUR 74.63. The total rental price distribution for Riga is in line with the normal one (Shapiro-Wilk test, $p=0.09$ ).

Warsaw was the last city analysed in terms of the distributions of total rental prices of private housing resources. The distribution of the total prices here remains in line with the normal one, at the mean total price amounting to EUR 58.01. Regarding the capital of Poland, $4 \%$ of the rental offers are outliers or suspected of being ones; $25 \%$ are under EUR 51.58, while $25 \%$ of them exceed EUR 62.81. It also needs noting for the City of Warsaw, a relatively narrow range of $95 \%$ of trust in the average amounting to between EUR 55.32 and 60.70 (cf. Figure 14).

Summing up, from the point of view of the mean value, the most expensive cities are Tallinn and Bratislava (with the mean total rental prices over 


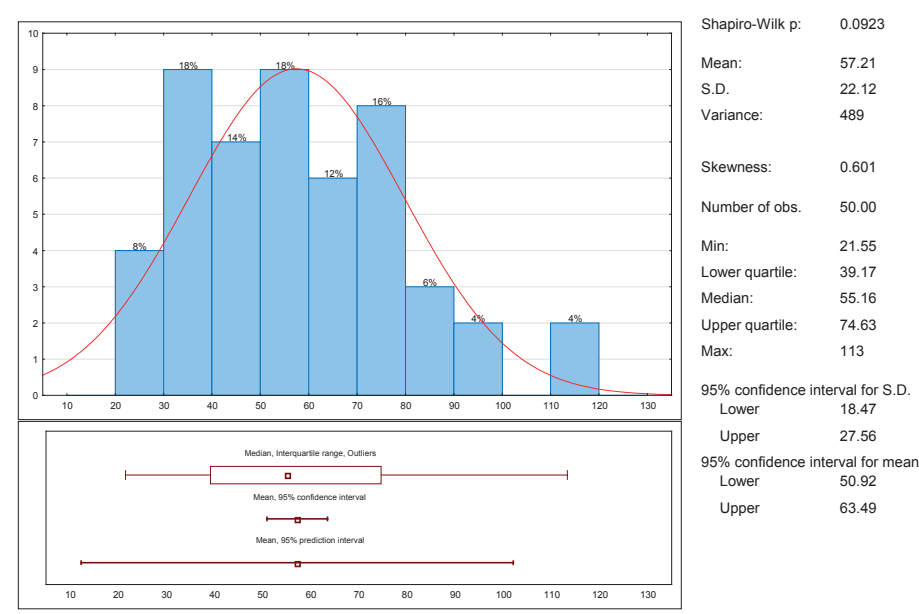

Fig. 13. Analysis of the total price distribution for the city of Riga

Source: own study based on calculations in Dell ${ }^{\mathrm{TM}}$ Statistica $^{\mathrm{TM}}$.

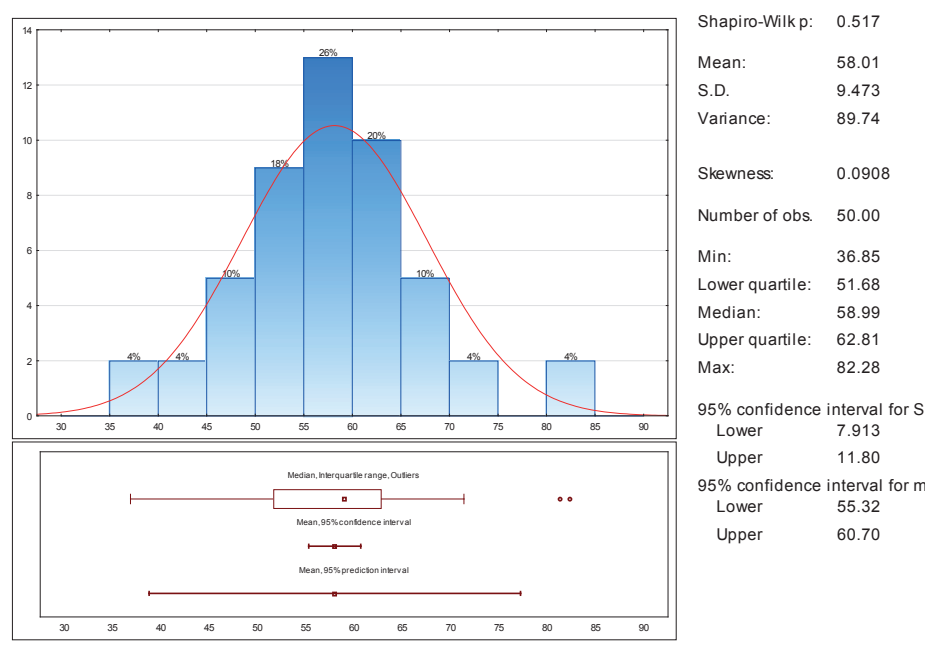

Fig. 14. Analysis of the total price distribution for the city of Warsaw

Source: own study based on calculations in Dell ${ }^{\mathrm{TM}}$ Statistica $^{\mathrm{TM}}$.

EUR 60). On the other hand, one will pay the least in the capitals of Bulgaria and Romania: mean total rental prices in Sofia and Bucharest oscillate below the level of EUR 50 and amount to EUR 49.48 and EUR 43.04, respectively. Part of the examined distributions of the total prices of rentals in the analysed 
cities were characterized by a symmetric distribution (Budapest, Bucharest, Bratislava, Prague, Tallinn, Riga, Warsaw), the city of Vilnius had a rightskewed distribution, whereas Sofia - a left-skewed distribution. One can thus accept that in the case of Vilnius there is a surplus of rental offers below the mean market value, whereas in the case of Sofia - above the mean market value.

\section{COMPARATIVE ANALYSIS OF THE MEAN PRICES IN THE CAPITAL CITIES OF CEE STATES}

The next stage of the study consisted in conducting a comparative analysis of the mean total prices of the offers in the nine examined capitals of excommunist states and in determining the significance of their differences.

To check the significance of differences in mean prices the variance analysis (ANOVA) was applied. Figure 15 presents the least squares means and Table1 shows one-dimension significance tests, size effects and powers for prices for accommodation per day (in euros). One can infer from the obtained results that there exists a statistically significant difference in the values of mean total prices. It follows from Figure 15 that Sofia and Bucharest are the capital cities with significantly different values of mean total rental prices.

Current effect: $F(8,441)=9,4326, p=, 00000$

Vertical bars denote 0,95 confidence interval

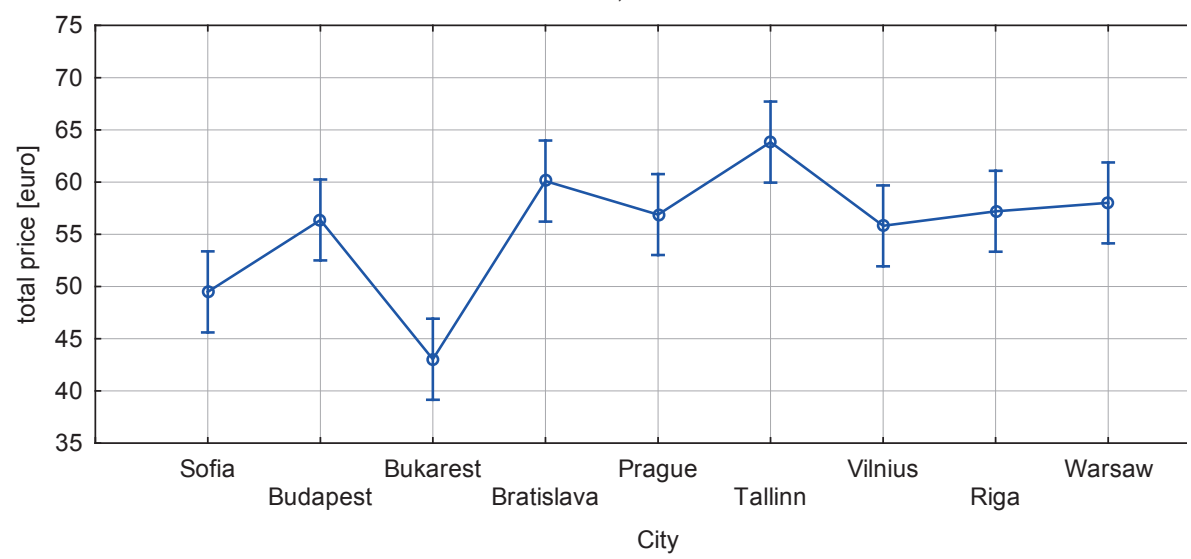

Fig. 15. Means for a main effect

Source: own study based on calculations in Dell ${ }^{\mathrm{TM}}$ Statistica ${ }^{\mathrm{TM}}$. 
In the next step of the research, while checking the significance of the differences in the mean total prices of the examined offers, two cities with the lower value of the mean total rental price, that is Sofia and Bucharest, were removed from the analysis.

Table 1

One-dimensional significance tests, effect sizes for price per person [in euros]

\begin{tabular}{l|c|c|c|c|c}
\hline \multicolumn{1}{c|}{ Effect } & Sum of squares & Degrees of freedom & Mean square & F & p-value \\
\hline Intercept & 1392909 & 1 & 1392909 & 7155.15 & 0.000 \\
\hline Name of city & 14690 & 8 & 1836 & 9.433 & 0.000 \\
\hline Error & 85850 & 441 & 195 & & \\
\hline
\end{tabular}

Source: own study based on calculations in Dell ${ }^{\mathrm{TM}}$ Statistica $^{\mathrm{TM}}$

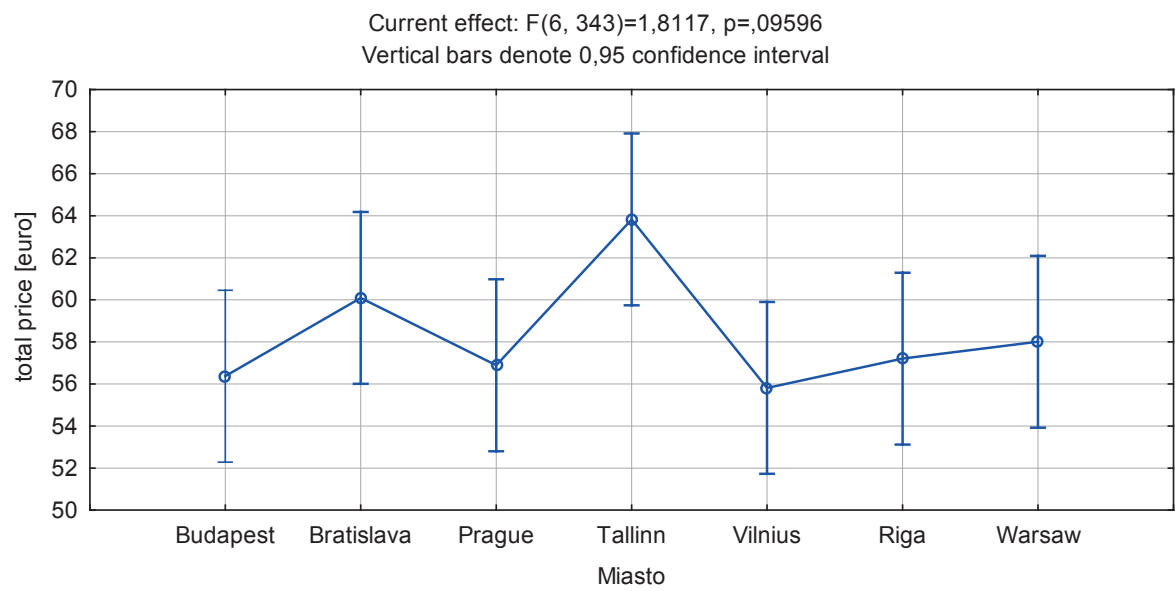

Fig. 16. Means for a main effect

Source: own study based on calculations in Dell ${ }^{\mathrm{TM}}$ Statistica ${ }^{\mathrm{TM}}$.

Figure 16 presents least squares means and Table 2 contains onedimensional significance tests, effect sizes and powers for the parameter of price for accommodation per day (in euros). It can be concluded on the basis of the obtained results that when comparing the mean rental prices in Budapest, Bratislava, Prague, Tallinn, Vilnius and Warsaw, the differences between them are not statistically significant. Thus one can conclude that in the seven above-mentioned cities the total rental prices are found to be close to one another. 
Table 2

One-dimensional significance tests, effect sizes for price per person [in euros]

\begin{tabular}{l|c|c|c|c|c}
\hline \multicolumn{1}{c|}{ Effect } & Sum of squares & Degrees of freedom & Mean square & F & p-value \\
\hline Intercept & 1190222 & 1 & 1190222 & 5513.77 & 0.000 \\
\hline Name of city & 2346 & 6 & 391 & 1.812 & 0.096 \\
\hline Error & 74041 & 343 & 216 & & \\
\hline
\end{tabular}

Source: own study based on calculations in Dell ${ }^{\mathrm{TM}}$ Statistica $^{\mathrm{TM}}$

\section{CONCLUSION}

The initial statistical analysis of the data in the present study focuses on the values of the mean total prices. The mean total price was calculated for several parameters forming the cost of rental of a private accommodation facility. The first parameter is the offered mean price for accommodation rental for one hotel day, the second - the fee charged for the service and the third one - the fee charged for cleaning. The final (total) price of the rental is the sum of the above-mentioned components.

Concluding, it can be said that the offered mean rental price in the capitals of CEE states remains at the level of EUR 20.14, whereas upon adding extra charges (service and cleaning) the mean total price rises to EUR 55.64. Finally, a price above EUR 50 charged for renting accommodation for one day is comparable with offers in the hotel market. However, it must be remembered that the B\&B type resources - in the majority of cases - give prices for the whole facility and not prices for one person as is accepted in the market of hotel services. Accordingly, the market of the B\&B type rental is one of similar cost values in the case of renting the facility for one or two persons. However, the higher the number of people who are using the offer of accommodation rental at the same time, the more advantageous the $\mathrm{B} \& \mathrm{~B}$ market is, taking into account the criterion of costs of rental per person.

To provide more detail, the formation of mean total prices of accommodation rental in the nine capitals of CEE countries which are members of the European Union was checked. To sum up and describe the individual cities, the assumption was accepted about conducting a comparative analysis taking into account the geolocation criterion. Considering the calculated mean total prices of the B\&B type of accommodation rental for the former Soviet republics, one can note that the highest prices were found in Tallinn (the mean total rental price of EUR 63.83); Vilnius (EUR 55.81) turned out the cheapest capital city among those of the former Soviet republics; Riga is characterized by the mean 
total rental price amounting to EUR 57.21. An additional conclusion from the conducted studies is the fact that Tallinn is the most expensive of all the examined capitals of the CEE countries belonging to the EU. Having analysed the mean total prices of accommodation rental for other capitals of Central European countries, i.e. Warsaw, Prague, Bratislava and Budapest, it can be concluded that the most expensive of them is Bratislava (EUR 60.09), then Warsaw (EUR 58.01). Prague (EUR 56.89) and Budapest (EUR 56.37). The lowest prices were found in the capital of the states which accessed the EU last , that is Romania and Bulgaria: the total prices of short-term accommodation rental remain at the level of EUR 43.04 in Bucharest and EUR 49.48 in Sofia. It should be pointed out that in the case of these two capitals the mean rental prices of private accommodation resources are below EUR 50.

The analysis of the significance of the differences in the mean prices proves that Bucharest and Sofia, statistically, differ from the values of mean rental prices in comparison with the other examined capitals. The information ending the analysis of the values of the mean total prices of accommodation rental in the nine capital cities is presentation of the $95 \%$-wide range of trust for the obtained mean values of total rental prices (cf. Table 3).

Table 3

Confidence internal for mean [in euros]

\begin{tabular}{l|c|c}
\hline \multirow{2}{*}{ City } & \multicolumn{2}{|c}{ Confidence interval - mean (95\%) } \\
\cline { 2 - 3 } & from & to \\
\hline Tallinn & 59.50 & 68.15 \\
\hline Bratislava & 56.08 & 64.11 \\
\hline Warsaw & 55.32 & 60.70 \\
\hline Riga & 50.92 & 63.59 \\
\hline Prague & 53.15 & 60.63 \\
\hline Budapest & 54.18 & 58.57 \\
\hline Vilnius & 51.16 & 60.46 \\
\hline Sofia & 46.32 & 52.65 \\
\hline Bucharest & 39.96 & 46.11 \\
\hline
\end{tabular}

Source: own study based on calculations in Dell ${ }^{\mathrm{TM}}$ Statistica $^{\mathrm{TM}}$.

From the viewpoint of the conducted analyses, the 95\%-wide trust range relating to the mean value presents the scope of prices offered by $95 \%$ of the facilities designed for rental within the sphere of the B\&B type. 
The research allowed for executing the parametrization of the price formation in the market of the rental of private accommodation resources of the $\mathrm{B} \& \mathrm{~B}$ type, confirming the conclusions drawn from the analysis of the literature, which prognosticate that rentals based on the principles of a sharing economy will considerably influence the market of hotel services, bringing about changes in the applied business models or ones in the price policy of the classic hotel services market. It should also be stressed that rentals based on the peer-to-peer technology will bring changes in the preferences and expectations of clients who use hotel services. Such changes will also result from other features of using the B\&B resources in comparison with those of the classic hotel services market. Undoubtedly, they will provide the subject of further studies in the near future.

Concluding, it should be stressed that the conducted research was narrowed down only to the analysis of the formation of the rental prices and their distribution. This study does not present other significant features of the rental accommodation resources which could influence their perception. In future, this research could be complemented with an analysis of the attributes of the offered rentals, that is the standard of accommodation on offer, the furnishings and equipment, as well as evaluations by clients who make use of it. The research was also limited from the point of view of geolocalization, covering the area of Central and Eastern Europe. An in-depth analysis of this market, aimed at presenting a fuller geolocalization picture, will be made for other regions in the future.

\section{REFERENCES}

Aczel, A. D., Complete Business Statistics, Richard D. Irwin, Boston, ISBN 0-256-05716-8, 1989.

Böcker, L., Meelen, T., Sharing for people, planet or profit? Analysing motivations for intended sharing economy participation, "Environmental Innovation and Societal Transitions", 2016.

Brochado, A., Troilo, M., Shah, A., Airbnb customer experience: Evidence of convergence across three countries, "Annals of Tourism Research", Vol. 63, pp. 210-212, 2017.

Cheng, M., Sharing economy: A review and agenda for future research, "International Journal of Hospitality Management", Vol. 57, pp. 60-70, 2016.

Cockayne, D. G., Sharing and neoliberal discourse: The economic function of sharing in the digital on-demand economy, "Geoforum", Vol. 77, pp. 73-82, 2016.

Daunorienè, A., Drakšaitè, A., Snieška, V., Valodkienė, G., Evaluating Sustainability of Sharing Economy Business Models, "Procedia - Social and Behavioural Sciences", Vol. 213, pp. 836-841, 2015. 
Dyal-Chand, R., Regulating Sharing: The Sharing Economy as an Alternative Capitalist System, "Tulane Law Review", North Eastern University School of Law Research Papers, Vol. 90, No. 2, pp. 241-309, 2015.

Ert, E., Fleischer, E., Magen, N., Trust and reputation in the sharing economy: The role of personal photos in Airbnb, "Tourism Management", Vol. 55, pp. 62-73, 2016.

Fang, B., Ye, Q., Law, R., Effect of sharing economy on tourism industry employment, "Annals of Tourism Research", Vol. 57, pp. 264-267, 2016.

Freedman, D., Pisani, R., Purves, R., Statistics, W. W. Norton \& Company, New York, ISBN 0-393-09076-0, 1980.

Frenken, K., Schor, J., Putting the sharing economy into perspective, "Environmental Innovation and Societal Transitions", Vol. 23, pp.3-10, 2017.

Gregory, A., Halff, G., Understanding public relations in the 'sharing economy', "Public Relations Review", Vol. 43, Issue 1, pp. 4-13, 2017

Guttentag, D. A., Smith, S. L. J., Assessing Airbnb as a disruptive innovation relative to hotels: Substitution and comparative performance expectations, "International Journal of Hospitality Management", Vol. 64, pp. 1-10, 2017.

Habibi, M. R., Davidson, A., Laroche, M., What managers should know about the sharing economy, "Business Horizons", Vol. 60, Issue 1, pp. 113-121, 2017.

Kathan, W., Matzler, K., Veider, V., The sharing economy: Your business model's friend or foe?, "Business Horizons", Vol. 59, Issue 6, pp. 663-672, 2016.

Koopman, Ch., Mitchell, M. D., Thierer, A. D., The Sharing Economy and Consumer Protection Regulation: The Case for Policy Change, "The Journal of Business, Entrepreneurship \& The Law", Vol. 8, Issue 2, 2015.

Kung L. Ch., Zhong, G. Y., The optimal pricing strategy for two-sided platform delivery in the sharing economy, "Transportation Research Part E: Logistics and Transportation Review", Vol. 101, pp. 1-12, 2017.

Liang, S., Schuckert, M., Law R., Chen Ch. Ch., Be a "Superhost": The importance of badge systems for peer-to-peer rental accommodations, "Tourism Management", Vol. 60, pp. 454-465, 2017.

Martin, Ch. J., The sharing economy: A pathway to sustainability or a nightmarish form of neoliberal capitalism?, "Ecological Economics", Vol. 121, pp. 149-159, 2016.

Ranchordas, S., Does Sharing Mean Caring? Regulating Innovation in the Sharing Economy, "Minnesota Journal of Law, Science \& Technology", Vol. 15, Issue 1, pp. 413-475, 2015.

Varma, A., Jukic, N., Pestek, A., Shultz, C. J., Nestorov, S., Airbnb: Exciting innovation or passing fad?, "Tourism Management Perspectives", Vol. 20, pp. 228-237, 2016.

Wang, D., Nicolau, J. L., Price determinants of sharing economy based accommodation rental: A study of listings from 33 cities on Airbnb.com, "International Journal of Hospitality Management", Vol. 62, pp. 120-131, 2017.

Wu, X., Zhi, Q., Impact of Shared Economy on Urban Sustainability: From the Perspective of Social, Economic, and Environmental Sustainability, "Energy Procedia", Vol. 104, pp. 191-196, 2016.

Received: December 2017, revised: April 2018 